\title{
Newborn Female with Hypoxic Respiratory Failure and Persistent Pulmonary Hypertension: A Case Report
}

\author{
Shang L. Lian ${ }^{a^{*}}$, Mubariz Naqvi ${ }^{a}$, Debdeep Banerjee ${ }^{b}$, Erika Allen ${ }^{b}$ and Amanda D. Griffin ${ }^{a}$ \\ ${ }^{a}$ Department of Pediatrics, Texas Tech University Health Sciences Center at Amarillo, Amarillo, TX, \\ USA \\ ${ }^{b}$ School of Medicine, Texas Tech University Health Sciences Center at Amarillo, Amarillo, TX, USA
}

\begin{abstract}
Streptococcus pneumoniae (SP) is a rare but well recognized cause of sepsis in neonates. Persistent pulmonary hypertension of newborn (PPHN) is one of the serious complications of SP and a frequent cause for morbidity and mortality in neonatal SP sepsis. It is a state of oxygenation failure characterized by high pulmonary vascular resistance with right-to-left shunting of venous blood. Inhaled NO (iNO) and extracorporeal membrane oxygenation (ECMO) have proven beneficial to infants who failed to respond to ventilation. Here we report a case of SP sepsis. The patient was a term female, who presented with rapidly progressing respiratory failure that occurred hours after birth. She subsequently developed severe PPHN, which did not respond adequately to ventilation and iNO. The patient was intermittently manually ventilated over a 3-hour period to keep $\mathrm{SpO}_{2}$ at $50-70 \%$. She had leukopenia, bandemia, elevated inflammatory markers, and positive blood culture for SP. Ampicillin and meropenem were administered to treat fulminant sepsis. She was transferred to a Level IV NICU in urgent need of ECMO. After transport, she improved on conventional ventilator and iNO without ECMO, and was discharged home on room air on day of life 39. The patient is currently a 12-month-old healthy female without any developmental issues.
\end{abstract}

Keywords: Neonate, sepsis, Streptococcal pneumoniae, pulmonary hypertension, extracorporeal membrane oxygenation.

\section{CASE REPORT}

A female infant was born by normal vaginal delivery at 39 weeks with Apgar scores of 7 at 1 minute and 8 at 5 minutes. The primigravid mother was treated for a urinary tract infection antenatally. The mother was healthy prior to the onset of labor and had no obvious signs of infection. The infant developed respiratory distress about 4-5 hours after delivery and required intubation at $<12$ hours of life $(\mathrm{HOL})$. The infant had leukopenia $\left(\mathrm{WBC}=3.4 \times 10^{3}\right)$ and significant bandemia with a ratio $(\mathrm{I} / \mathrm{T})$ of immature neutrophils (band cells + myelocytes + metamyelocytes) to total neutrophils of 0.87 . A blood culture sample was obtained before administering an antibiotic regime that included ampicillin, gentamicin, and cefotaxime. The neonate was transferred to the regional neonatal intensive care unit (NICU) on day of life (DOL) 2.

Upon arrival, the infant developed severe persistent pulmonary hypertension (PPHN) as

*Address correspondence to Shang L. Lian; Department of Pediatrics, 1400 S. Coulter Street, Amarillo, TX 79106, USA; Tel: 806-414-9786; Fax: 806-354-5536;

Email: slian@valleychildrens.org, Jessellian01@hotmail.com demonstrated by echocardiogram. She required intensive ventilatory support, inotropic support (dopamine and dobutamine), and a pulmonary vasodilator (inhaled nitric oxide [iNO]). Her peripheral capillary oxygen saturation $\left(\mathrm{SpO}_{2}\right)$ continued to drop to as low as $10 \%$. She was in severe hypoxemia and respiratory acidosis with a partial pressure of oxygen $\left(\mathrm{pO}_{2}\right)$ as low as $18 \mathrm{~mm}$ $\mathrm{Hg}$ and $\mathrm{a} \mathrm{pH}$ lower than 7.0 in arterial blood over a 3-hour period (Table 1, HOL 27-HOL 29.5). The oxygenation index (OI) was high at 60-70. A chest $X$-ray revealed moderate bilateral reticulogranularity. Surfactant therapy did not improve her hypoxic respiratory failure. Manual ventilation, with bag and mask, was more effective than mechanical ventilation in keeping $\mathrm{SpO}_{2}$ levels between $50-70 \%$. Transfer to a higher level $\mathrm{NICU}$, equipped with extracorporeal membrane oxygenation (ECMO), was considered, but delayed, initially due to weather and later because her condition improved on DOL 3 . The antibiotics regimen was changed to meropenem at the dose used to treat meningitis upon arriving at regional NICU due to severe sepsis/meningitis. Lumbar puncture was not performed because of the critical nature of the infant's condition. Inflammatory markers, including serum pro- 
Table 1: Blood Gas from Capillary (CBG) or Artery Blood (ABG) During First 2 Days of Life

\begin{tabular}{|c|c|c|c|c|c|c|}
\hline & $\begin{array}{l}\text { Hours of Life } \\
\text { (HOL) }\end{array}$ & pH & $\begin{array}{c}\mathrm{pCO}_{2} \\
\mathrm{~mm} \mathrm{Hg}\end{array}$ & $\begin{array}{c}\mathrm{pO}_{2} \\
\mathrm{~mm} \mathrm{Hg}\end{array}$ & $\begin{array}{l}\mathrm{HCO}_{3} \\
\mathrm{mEq} / \mathrm{L}\end{array}$ & $\begin{array}{c}\text { Base Excess } \\
\mathrm{mEq}\end{array}$ \\
\hline \multirow[t]{2}{*}{ CBG } & HOL 18 & 7.16 & 58.0 & & 21 & -8 \\
\hline & HOL 23 & 7.30 & 39.4 & & 20 & -6 \\
\hline \multirow[t]{11}{*}{$A B G$} & HOL 26 & 7.04 & 66.2 & 18 & 18 & -13 \\
\hline & HOL 27 & 6.97 & 57.6 & 24 & 13 & -18 \\
\hline & HOL 27.5 & 6.98 & 61.2 & 28 & 14 & -17 \\
\hline & HOL 28 & 6.91 & 82.0 & 26 & 16 & -17 \\
\hline & HOL 29 & 6.92 & 83.3 & 38 & 17 & -15 \\
\hline & HOL 29.5 & 6.95 & 89.3 & 27 & 20 & -12 \\
\hline & HOL 32 & 7.02 & 75.2 & 30 & 19 & -12 \\
\hline & HOL 35 & 7.19 & 51.9 & 36 & 20 & -8 \\
\hline & HOL 38 & 7.21 & 51.0 & 37 & 21 & -7 \\
\hline & HOL 39 & 7.26 & 46.8 & 63 & 21 & -6 \\
\hline & HOL 43 & 7.34 & 40.0 & 91 & 22 & -4 \\
\hline
\end{tabular}

calcitonin (49.79 $\mathrm{mcg} / \mathrm{L}), \mathrm{CRP}(52.7 \mathrm{mg} / \mathrm{L})$, and interleukin-6 $(53,152.1 \mathrm{pg} / \mathrm{ml})$ were markedly elevated. On DOL 3 , blood culture results from the referral hospital (obtained prior to initiation of antibiotics) showed growth of gram-positive cocci in chains. Ampicillin $(100 \mathrm{mg} / \mathrm{kg} /$ dose every 12 hours) was added to meropenem to cover Group $B$ streptococcus (GBS) since it is the most common pathogen of neonatal sepsis. A pediatric infectious disease subspecialist was consulted, who recommended continuing the meropenem/ ampicillin regimen after the pathogen was identified as penicillin-sensitive Streptococcus pneumoniae (SP) to make sure both GBS and SP were covered.

On DOL 6 the infant's PPHN and hypoxic respiratory distress were again aggravated. She had significant right-to-left shunting with preductal $\mathrm{SpO}_{2} \quad 20 \%$ higher than postductal. Pressure support agents including dobutamine and dopamine were re-initiated. Inhaled NO was increased from $20 \mathrm{ppm}$ to $40 \mathrm{ppm}$. In spite of the maximum ventilation with a mechanical ventilator, her postductal $\mathrm{SpO}_{2}$ dropped to $40 \%$. She was resuscitated using bag and mask for 30 minutes. Due to concern of uncontrolled sepsis, meropenem was discontinued. Cefotaxime and vancomycin were started at the dose used to treat meningitis to cover penicillin-resistant SP.

To make ECMO possible, the infant was airlifted to a level IV NICU. Due to improvement in oxygenation and resolution of PPHN, ECMO was not conducted. She received iNO until DOL 14, was extubated on DOL 15, reached full feeds on DOL 19, was weaned to room air on DOL 37 , and discharged on DOL 39. Cerebrospinal fluid obtained on DOL 13 was within normal limits without pleocytosis. The culture of cerebrospinal 
fluid was negative. Intravenous antibiotics were discontinued on DOL 21. She had a normal head ultrasound and hearing screening, and ageappropriate cognition and neurodevelopment. She had a small atrial septal defect, which did not warrant intervention.

The patient did well after discharge. Her follow-up with cardiology revealed $1 / 6$ systolic murmur with $>95 \% \mathrm{SpO}_{2}$ and no signs of residual PPHN. At her well-child visits of 2-, 4-, 6-, and 9-months, she demonstrated appropriate growth and development. She is currently 12 -months-old and continues to thrive.

\section{DISCUSSION}

SP is a rare, but well recognized cause of sepsis in neonates [1-8] and is associated with significant morbidity and mortality. The clinical presentation and symptoms are non-specific and can be similar to GBS disease. In developed countries, SP accounts for $1-11 \%$ of neonatal sepsis $[2,9]$. Early-onset SP sepsis is less common than lateonset SP sepsis and has a more dire prognosis, especially when it starts before $48 \mathrm{HOL}$ or is secondary to an invasive maternal infection [6]. Mortality from early-onset SP sepsis was reported as $14.3 \%$ in one study and was not related to pneumococcal serogroup or susceptibilities [2]. Treatment options differ depending on penicillin sensitivity of SP. The local sensitivity pattern of SP is helpful in directing empirical antibiotic selection (Table 2).

Pneumococcal conjugate vaccine (PVC7) was introduced in 2000, and covers seven serotypes of the bacteria $(4,6 \mathrm{~B}, 9 \mathrm{~V}, 14,18 \mathrm{C}, 19 \mathrm{~F}$, and $23 \mathrm{~F})$. In 2010, pneumococcal conjugate 13-valent vaccine (PCV-13) advanced the coverage to 6 additional serotypes (1, 3, 5, 6A, 7F, and 19A). The cost benefit of PCV-13 won't be seen until the

Table 2: Local Sensitivity Pattern of Streptococcus pneumoniae and other Pathogens in Inpatient Population of the Regional Hospital

\begin{tabular}{|c|c|c|c|c|c|c|c|c|c|c|c|c|c|c|c|c|}
\hline $\begin{array}{c}\% \text { Sensitive } \\
\text { Systemic } \\
\text { Gram + } \\
\text { Infections } \\
\text { Cumulative } \\
\text { Incidence at } \\
\text { Regional } \\
\text { Hospital }\end{array}$ & 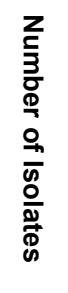 & $\begin{array}{l}\text { D } \\
\text { D. } \\
\overline{\bar{D}} \\
\overline{\bar{\Xi}}\end{array}$ & 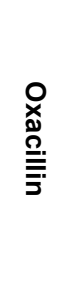 & 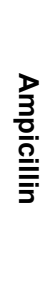 & 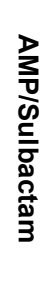 & 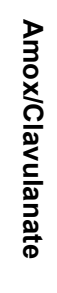 & 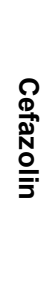 & 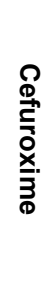 & 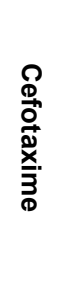 & 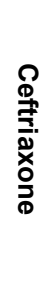 & 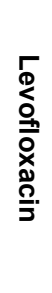 & $\begin{array}{l}\text { m } \\
\stackrel{5}{\mathbf{2}} \\
\mathbf{5} \\
\frac{0}{3} \\
\stackrel{0}{3}\end{array}$ & 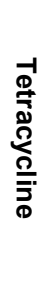 & 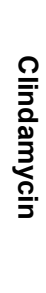 & 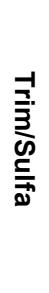 & 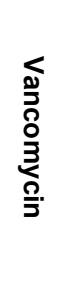 \\
\hline $\begin{array}{c}\text { Enterococcus } \\
\text { faecalis }\end{array}$ & 163 & 99 & & 99 & & & & & & & 75 & 19 & 21 & & & 99 \\
\hline $\begin{array}{l}\text { Enterococcus } \\
\text { fecium }\end{array}$ & 43 & 42 & & 42 & & & & & & & 35 & 5 & 42 & & & 49 \\
\hline MSSA* $^{*}$ & 707 & 23 & 100 & 21 & 99 & 99 & 98 & & & 99 & 88 & 67 & 94 & 93 & 98 & 100 \\
\hline $\mathrm{MRSA}^{* *}$ & 573 & & & & & & & & & & 29 & 11 & 90 & 72 & 97 & 100 \\
\hline $\begin{array}{l}\text { Staphylococcus } \\
\text { epidermidis }\end{array}$ & 242 & 7 & 28 & 5 & 28 & 28 & 28 & & & 28 & 57 & 30 & 86 & 61 & 61 & 100 \\
\hline $\begin{array}{c}\text { Pen + } \\
\text { Streptococcus } \\
\text { pneumoniae }\end{array}$ & 160 & 100 & & & & 100 & & 99 & 100 & 99 & 99 & 76 & 90 & 96 & 87 & 100 \\
\hline $\begin{array}{c}\text { Pen - } \\
\text { Streptococcus } \\
\text { pneumoniae }\end{array}$ & 79 & & & & & 91 & & 41 & 92 & 94 & 95 & 27 & 51 & 72 & 46 & 100 \\
\hline $\begin{array}{l}\text { Viridans } \\
\text { Streptococcus } \\
\text { group }\end{array}$ & 117 & 61 & & 62 & & & & & 93 & 95 & 89 & 41 & 70 & 89 & & 100 \\
\hline
\end{tabular}

Blank cell indicates: data are not available or drug is not appropriate for pathogen; * Methicillin Sensitive Staphylococcus aureus; ${ }^{* *}$ Methicillin Resistant Staphylococcus aureus; Pen = Penicillin. 
vaccinated children reach childbearing age. In our case, the mother was not vaccinated. The serotype of SP in the current case was not determined. It would be of interest to know the serotype of the pathogen that caused early onset neonatal sepsis in the era of PCV-13 [10].

The source of the infection in neonatal early-onset $\mathrm{SP}$ sepsis is almost invariably from the maternal birth canal, although SP is an unusual component of vaginal flora $[4,9,11]$. The colonization rate is extremely low $(\leq 0.03 \%)$ [11]. Thirty percent of mothers of infants with early-onset invasive SP infection had clinical signs of infection [12]. The invasiveness of the maternal SP infection positively correlated with the severity of neonatal disease [6]. In our case, we were told that the mother required antibiotic treatment for a postpartum febrile illness. We were unable to access the mother's medical record and did not have the details of her illness. A culture of vaginal secretions or amniotic fluid was not conducted, but could have given us more information about the source of infection.

In neonatal sepsis, endotoxin released by the pathogenic bacteria contributes to the development of PPHN, a frequent cause for NICU admission. PPHN is primarily a state of oxygenation-failure characterized by high pulmonary vascular resistance with right-to-left shunting of venous blood and is associated with right ventricle dysfunction. Surviving neonates often require prolonged cardiorespiratory support, long hospital stays, and are at high risk of longterm adverse neurodevelopmental outcomes [13]. $\mathrm{ECMO}$ and iNO are beneficial to infants who fail to respond to ventilation [14-16]. iNO is a selective pulmonary vasodilator that produces a rapid and sustained improvement in systemic oxygenation without excessive hypocapnia and reduces the overall need for ECMO [16].

Our patient is the first case of SP sepsis in our NICU over the past 30 years. The presentation was non-specific and akin to GBS sepsis with a very rapid progression. Her PPHN and hypoxic respiratory failure were intractable. With an OI constantly higher than 40 and poor response to ventilation or iNO, she was a candidate for ECMO. Of note, was the observation that manual ventilation with bag and mask seemed to be more effective to improve $\mathrm{SpO}_{2}$ than mechanical ventilation during the critical hypoxic period. The patient was intermittently manually ventilated over a 3-hour period on DOL 2 to keep $\mathrm{SpO}_{2}$ between $50-70 \%$. Manual ventilation by an experienced physician can easily adjust mean airway pressure and inspiratory time according to the patient's breathing. It is more flexible and can meet patient's oxygenation needs faster than mechanical ventilation. The neurodevelopment of our patient was a concern, since she had significant hypoxemia $\left(\mathrm{pO}_{2} 18-38 \mathrm{~mm} \mathrm{Hg}\right)$ and hypercapnia $\left(\mathrm{pCO}_{2} 51-89 \mathrm{~mm} \mathrm{Hg}\right)$ over an 11hour period on DOL 2 and 3. Currently, she is 12months-old and continues to thrive without demonstrating any cognitive or developmental issues. It is possible that avoiding hypocapnia protected her brain. Alternatively, the blood that supplied her brain was pre-ductal and might have contained a higher oxygen content.

\section{CONCLUSION}

$\mathrm{SP}$ is an uncommon, but well recognized cause of sepsis in newborns and should promptly be considered as part of a differential diagnosis for neonatal early-onset sepsis. ECMO should be considered in a patient with severe PPHN who does not respond to ventilation and iNO therapy.

\section{REFERENCES}

[1] Sallam A, Paes B. Streptococcus pneumoniae: an old bug with significant maternal-newborn implications. Am J Perinatol 2004; 21: 491-5.

[2] Hoffman JA, Mason EO, Schutze GE, et al. Streptococcus pneumoniae infections in the neonate. Pediatrics 2003; 112: 1095-102.

[3] Malhotra A, Hunt RW, Doherty RR. Streptococcus pneumoniae sepsis in the newborn. J Paediatr Child Health 2012; 48: E79-83.

[4] Rodriguez BF, Mascaraque LR, Fraile LR, Perez IC, Kuder K. Streptococcus pneumoniae: the forgotten microorganism in neonatal sepsis. Fetal Pediatr Pathol 2015; 34: 202-5.

[5] Arora S, Kaur N, Galhotra S, Jindal N. Streptococcus pneumoniae: An unusual and forgotten pathogen in neonatal sepsis. Indian J Pathol Microbiol. 2016; 59: 573-4.

[6] Gomez M, Alter S, Kumar ML, Murphy S, Rathore MH. Neonatal Streptococcus pneumoniae infection: case reports and review of the literature. Pediatr Infect Dis $\mathrm{J}$ 1999; 18: 1014-8.

[7] McAdams RM, Garza-Cox S, Yoder BA. Early-onset neonatal pneumococcal sepsis syndrome. Pediatr Crit Care Med 2005; 6: 595-7.

[8] Alan S, Yıldız D, Erdeve O, Atasay B, Nar Otgun S, Ince $E$, Arsan $S$. An early neonatal sepsis case due to Streptococcus pneumoniae serotype 7F. Mikrobiyol 
Bul. 2013; 47: 158-63.

[9] Faust K, Demmert M, Bendiks M, Göpel W, Herting E, Härtel C. Intrapartum colonization with Streptococcus pneumoniae, early-onset sepsis and deficient specific neonatal immune responses. Arch Gynecol Obstet 2012; 285: 599-604.

[10] Fothy JF, Vetter S, Iñigo A, Gil J, Pérez JL, Hervás JA. Early-onset Streptococcus pneumoniae neonatal sepsis and meningitis in the 13-valent vaccine era. Pediatr Infect Dis J 2013; 32: 1299-300.

[11] Singh J, Dick J, Santosham M. Colonization of the female urogenital tract with Streptococcus pneumoniae and implications for neonatal disease. Pediatr Infect Dis J 2000; 19: 260-262.

[12] Westh H, Skibsted L, Korner B. Streptococcus pneumoniae infections of the female genital tract and in the newborn child. Rev Infect Dis 1990; 12: 416-22.

[13] osono S, Ohno T, Kimoto H, Shimizu M, Takahashi S,
Harada K. Developmental outcomes in persistent pulmonary hypertension treated with nitric oxide therapy. Pediatr Int 2009; 51: 79-83.

[14] Bennett CC, Johnson A, Field DJ, Elbourne D, UK Collaborative ECMO Trial Group. UK collaborative randomised trial of neonatal extracorporeal membrane oxygenation: follow-up to age 4 years. Lancet 2001; 357: 1094-96.

[15] McNally $H$, Bennett CC, Elbourne D, Field DJ; UK Collaborative ECMO Trial Group. UK collaborative randomized trial of neonatal extracorporeal membrane oxygenation: follow-up to age 7 years. Pediatrics 2006; 117: e845-54.

[16] Barrington KJ, Finer N, Pennaforte T, Altit G. Nitric oxide for respiratory failure in infants born at or near term. Cochrane Database Syst Rev. 2017; 5:CD000399. 